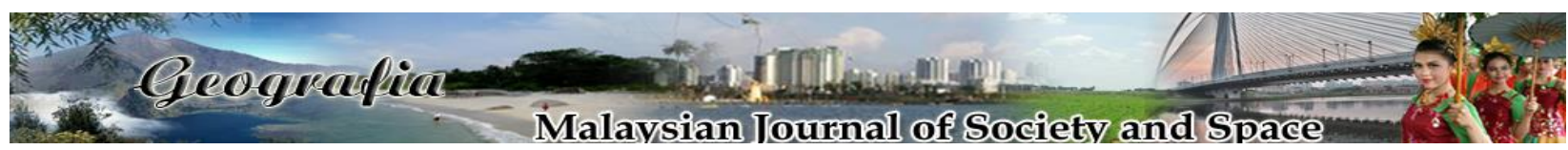

\title{
Perspektif Sosiologi Bidayuh Terhadap Gerakan Sabah Sarawak Keluar Malaysia (SSKM)
}

\author{
Novel Lyndon \\ Program Antropologi dan Sosiologi, Pusat Pembangunan, Sosial dan Persekitaran, \\ Fakulti Sains Sosial dan Kemanusiaan, Universiti Kebangsaan Malaysia \\ Correspondence: Novel Lyndon (email: novel@ukm.edu.my)
}

Received: 15 November 2019; Accepted: 22 November 2019; Published: 25 November 2019

\begin{abstract}
Abstrak
Ketidaksamarataan sosial atas dasar diskriminasi, peminggiran dan pengasingan hingga menimbulkan jurang kemiskinan antara negeri dan wilayah seringkali dibangkitkan dalam hubungan antara negeri dan kerajaan persekutuan. Dalam masa yang sama, polemik ini kemudiannya dihangatkan lagi dengan perjanjian tentang status dan hak antara negeri dan kerajaan persekutuan menurut perundangan dalam pembentukan sesebuah negara bangsa. Objektif utama kajian ini ialah untuk meneliti perspektif etnik Bidayuh terhadap Gerakan Sabah Sarawak Keluar Malaysia (SSKM) berdasarkan imaginasi sosiologi dimensi diskriminasi, peminggiran dan pengasingan sebagai rakan kongsi dalam pembentukan negara Malaysia berasaskan Perjanjian 1963. Strategi penyelidikan abduktif menggunakan teknik pengumpulan data secara kualitatif iaitu temubual mendalam dan perbincangan kumpulan terfokus telah digunakan. Sejumlah 50 orang etnik Bidayuh di Bahagian Serian telah terlibat dalam kajian ini menggunakan persampelan berstrata dan bertujuan. Hasil kajian menunjukkan bahawa terdapat tiga perspektif utama yang diutarakan oleh etnik Bidayuh di Bahagian Serian tentang Gerakan Sabah Sarawak Keluar Malaysia iaitu untuk menuntut hak sebagai rakan sekutu dalam Pembentukan Negara Malaysia yang telah termaktub dalam Perjanjian Malaysia 1963 dan desakan terhadap kerajaan persekutuan supaya menghormati 18 perkara untuk Sarawak yang terkandung dalam Perjanjian Malaysia 1963 dan sebagai landasan untuk menyuarakan perasaan tidak puas hati terhadap pentadbiran kerajaan pusat yang berterusan menganaktirikan pembangunan rakyat di kedua-dua buah negeri ini. Kesimpulannya, pandangan ini timbul disebabkan oleh sikap kerajaan persekutuan itu sendiri yang masih lagi tidak mengimplimentasikan hak dan status negeri Sarawak dalam konteks perundangan sebagai rakan sekutu dalam pembentukan negara Malaysia.
\end{abstract}

Katakunci: diskriminasi, etnik Bidayuh, ketidaksamarataan sosial, peminggiran, Sarawak 


\title{
Sociological Perspectives on Sabah Sarawak Secession Movement of Malaysia (SSKM)
}

\begin{abstract}
Social inequality on the basis of discrimination, marginalization and alienation has led to gaps between state and territory poverty often raised in the relationship between the state and the federal government. At the same time, the debate was further strengthened by the agreement on the status and rights of state and federal governments in accordance with the constitution of the formation of a nation. The main objective of this study was to examine the Bidayuh ethnic perspective in relation to the Sabah Sarawak Secession Movement (SSKM) based on the sociological imagination dimensions of discrimination, marginalization and alienation as partners in the formation of the Malaysian nation under the 1963 Agreement. An abductive research strategy using qualitative data collection techniques including in-depth interviews and focused group discussions was used. A total of 50 Bidayuh ethnic groups in the Serian Division participated in this study using stratified and purporsive sampling. The results show that there are three main perspectives expressed by the Bidayuh ethnic groups in the Serian Division on Sabah Sarawak Secession Movement of Malaysia that is to claim the right to be an ally in the Formation of Malaysia as set out in the Malaysian Agreement 1963, urging the federal government to respect 18 points for Sarawak is embodied in the Malaysia Agreement of 1963 and as a basis for expressing dissatisfaction with the federal government's ongoing administration of the people's development in both states. In conclusion, this view is borne out by the attitude of the federal government itself which has yet to implement the rights and status of Sarawak in the legal context as an ally in the formation of Malaysia.
\end{abstract}

Keywords: discrimination, ethnic Bidayuh, social inequality, marginalization, Sarawak

\section{Pengenalan}

Gerakan Sabah Sarawak Keluar Malaysia (SSKM) dari imaginasi sosiologikalnya merujuk kepada ketidaksamarataan sosial hingga menyebabkan wujudnya konflik hubungan antara negeri dan persekutuan (Azizah 2009; Bilson, 1998; Catherine, 2014). Polemik ini kemudiannya dihangatkan dengan beberapa perkara yang dilihat tidak memihak kepada negeri Sarawak dan Sabah sebagai rakan kongsi atau rakan sekutu dalam membentuk negara Malaysia pada 16 September 1963 (Zainnal, 2015; Ismail, 1997). Perkara tersebut terdiri daripada Perjanjian Malaysia 1963 yang tidak dipatuhi, status Sabah dan Sarawak sebagai rakan atau negara tidak diikitiraf dari segi aplikasinya, ketidakadilan politik, hasil Sarawak dan Sabah dieksploitasi hingga menyebabkan kedua-dua negeri ini miskin, pembangunan yang tidak sama rata, ketidakadilan sosial, ketidaksamaan sosial kerajaan pusat kepada Sarawak dan Sabah dan isu kebebasan agama dan akhir sekali diskriminasi yang dijalankan oleh kerajaan pusat yang merangkumi ketidakbolehsampaian terhadap infrastruktur hingga mengabaikan kebajikan penduduk Sabah dan Sarawak (Ong \& Badariah, 2016; Jacqueline, 2014; Zainnal, 2015; Rosaini, 2009). Keadaan ini menyebabkan orang Sabah dan Sarawak mula berfikir untuk menuntut hak mereka sebagaimana yang terkandung dalam Perjanjian Malaysia 1963 melalui dua saluran NGO 
(Pertubuhan Bukan Kerajaan) iaitu Sabah Sarawak Keluar Malaysia (SSKM) dan Sabah Sarawak Union (SSU) (Zainnal, 2015; Lim, 2008; Zaini, 2010). Kedua-dua saluran NGO ini dianggap sebagai jalan yang terbaik dalam menyuarakan pandangan mereka tentang sikap diskriminasi dan ketidakadilan kerajaan pusat terhadap hak dan kebajikan orang Sabah dan Sarawak (Zainnal, 2015). Dalam masa yang sama juga, hak Orang Sabah dan Sarawak mengikut Memorandum Perkara 18/20 yang tidak dihormati oleh Kerajaan Pusat telah merancakkan lagi sentimen Sabah Sarawak keluar dari Malaysia (Bilson, 1998; Azizah, 2009). Menurut Zainnal (2015) dan Leong (1982), gerakan atau propaganda Sabah Sarawak Keluar Malaysia ini sememangnya sangat sinonim dengan Perjanjian Malaysia atau Malaysia Agreement (MA63). Perjanjian Malaysia 1963 ini adalah dokumen yang ditandatangani oleh pihak-pihak United Kingdom of Great Britain dan Northern Ireland, Persekutuan Tanah Melayu, Borneo Utara, Sarawak dan Singapura (Jabatan Perdana Menteri Malaysia, 2019). Perjanjian ini telah ditandatangani pada 9 Julai 1963 di London (Jabatan Perdana Menteri Malaysia, 2019).

\section{Kajian literatur}

\section{Perjanjian Malaysia 1963 dan kemunculan Gerakan Sabah Sarawak Keluar Malaysia (SSKM)}

Perjanjian Malaysia 1963 adalah merupakan satu perjanjian untuk membentuk Persekutuan Malaysia iaitu gabungan rakan sekutu antara Persekutuan Tanah Melayu bergabung bersama wilayah-wilayah Borneo Utara (Sabah), Sarawak dan Singapura (Rahman \& Pandikar, 2019; Zaini, 2010; Lim, 2008). Di dalam perjanjian ini terdapat 11 perkara yang menjadi intipati atau asas kepada perjanjian ini bagi membantu mewujudkan pembentukan kerajaan berasaskan semangat federalisme (Lim, 2008; Kasmila, 1980; Ramzah, 2010). Justeru itu, perkara pertama yang perlu dilakukan ialah Borneo Utara dan Sarawak dan Singapura akan disekutukan dengan Persekutuan Tanah Melayu dan dikenali sebagai Negeri Sabah, Negeri Sarawak dan Negeri Singapura mengikut surat cara Perlembagaan yang dilampirkan pada surat perjanjian dengan penamaan Persekutuan dengan nama "Malaysia" (Zainnal, 2015; Ramzah, 2010). Dengan erti kata lain, sistem politik di bawah konsep federalism ini adalah berasaskan prinsip rakan sekutu dan sistem politik demokratik melalui kaedah pilihanraya (Lim, 2008; Ong \& Badariah, 2016). Perkara kedua ialah menyatakan mengenai kewajipan Kerajaan Persekutuan Tanah Melayu untuk menggubal perlembagaan melalui Parlimen Persekutuan dengan memastikan surat cara Perlembagaan yang dilampirkan akan menjadi suatu Akta untuk dipatuhi di dalam Perlembagaan yang digubal dan akan berkuatkuasa pada 31 Ogos 1963 dan tarikh ini akan dikenali sebagai "Hari Malaysia". Perkara ketiga ialah menyatakan mengenai tanggungjawab kerajaan United Kingdom untuk menyerahkan kepada Queen, perintah-perintah untuk membolehkan Perlembagaan negeri-negeri Sabah, Sarawak dan Singapura berkuatkuasa mengikut lampiranlampiran perlembagaan setiap negeri. Perkara keempat ialah menyatakan mengenai kewajipan Kerajaan United Kingdom untuk mendapatkan penggubalan satu Akta di Parlimen United Kingdom bagi membolehkan perlepasan hak kedaulatan oleh Queen ke atas Borneo Utara, Sarawak dan Singapura, bermula pada "Hari Malaysia" dan diserahkan kuasa itu mengikut Perjanjian.

Perkara kelima ialah mengenai kewajipan Kerajaan Persekutuan Tanah Melayu untuk mendapatkan penggubalan Akta oleh Parlimen bagi meminda skop imigresen untuk kemasukan ke Sabah dan Sarawak serta peruntukan-peruntukan khas seperti lampiran yang tertentu yang 
dilampirkan bersama-sama Perjanjian ini akan tertakluk kepada penggubalan Akta tersebut. Perkara keenam ialah mengenai Perjanjian Pertahanan Luar dan Bantuan Bersama antara Persekutuan Tanah Melayu dan United Kingdom pada 1957, kini akan diperluaskan bagi semua wilayah "Malaysia" serta kebenaran untuk United Kingdom terus menggunakan pengkalanpengkalan tentera sedia ada terutamanya di Singapura, seperti mana dalam lampiran di dalam Perjanjian ini. Perkara ketujuh ialah menyatakan mengenai persetujuan bagi membolehkan Queen membuat perintah mengenai pembayaran saguhati kepada para pegawai dalam perkhidmatan awam yang berkhidmat, terutama di North Borneo dan Sarawak sebelum Hari Malaysia. Selain itu, ia turut menyentuh mengenai Perjanjian Pegawai Awam yang harus ditandatangani oleh Kerajaan United Kingdom dan Kerajaan Malaysia.

Kerajaan Malaysia juga hendaklah memperolehi persetujuan daripada Kerajaan Sabah, Sarawak atau Singapura sebelum menandatangani perjanjian itu. Perkara kelapan ialah mengenai tanggungjawab Kerajaan Persekutuan Tanah Melayu, Borneo Utara dan Sarawak untuk mengambil tindakan bagi melaksanakan segala syor, jaminan dan aku janji yang terdapat di dalam Bab III dan Lampiran A dan Lampiran B Laporan Jawatankuasa Antara Kerajaan yang ditandatangani pada 27 Februari 1963 selagi mana ia tidak dinyatakan di dalam Perlembagaan Persekutuan. Seterusnya dalam perkara kesembilan menyentuh tentang keperluan menjadikan Lampiran $\mathbf{J}$ berkenaan dengan Pasaran Bersama dan perkiraan kewangan di dalam perjanjian ini yang dijadikan sebagai Perjanjian antara Kerajaan Persekutuan Tanah Melayu dan Kerajaan Singapura. Perkara yang kesepuluh ialah menyatakan mengenai tentang keperluan Kerajaan Persekutuan Tanah Melayu dan Kerajaan Singapura dalam menjalankan kuasa-kuasa yang ada berkenaan dengan siaran radio dan televisyen seperti mana yang termaktub di dalam Lampiran $\mathrm{K}$ di dalam Perjanjian ini selagi ia tidak dilaksanakan melalui Perlembagaan Malaysia. Perkara yang kesebelas ialah menyatakan mengenai keperluan Perjanjian ini ditandatangani di dalam Bahasa Inggeris dan Bahasa Melayu sahaja manakala setiap lampirannya hanyalah di dalam Bahasa Inggeris. Jika kekeliruan berlaku, maka naskhah Bahasa Inggeris akan digunakan sebagai tafsiran yang sah.

Memorandum 20/18 Perkara juga adalah merupakan dokumen yang sangat penting bagi Sabah dan Sarawak (Ramli, 2003; Yee, 1991). Memorandum ini telah dikemukakan oleh Borneo Utara kepada Jawatankuasa Antara Kerajaan yang telah ditubuhkan pada bulan Ogos 1962 (Jabatan Perdana Menteri Malaysia, 2019). Jawatankuasa ini telah ditubuhkan hasil daripada cadangan Suruhanjaya Cobbold dan fungsi utamanya adalah untuk menjamin hak dan kepentingan rakyat Sabah dan Sarawak agar tidak tergugat apabila menyertai Malaysia (Lim, 2008; Rahman \& Pandikar, 2019; Matthew, 2009). Melalui jawatankuasa inilah, satu memorandum yang diberi nama "Dua Puluh Perkara" telah dihantar oleh Sabah, antara lainnya bertujuan untuk melindungi hak dan kepentingan Sabah di dalam Persekutuan Malaysia.

Sarawak pula telah bersetuju dengan perkara-perkara yang dinyatakan di dalam memorandum tersebut, terutamanya yang melibatkan kepentingan dan hak rakyat secara umum (Rahman \& Pandikar, 2019; Lim, 2008). Hasil daripada memorandum yang telah dihantar, Jawatankuasa Antara Kerajaan telah mengesyorkan perkara-perkara penting berikut untuk dipatuhi dan dimasukkan ke dalam Perlembagaan Persekutuan. Antaranya ialah Islam adalah agama rasmi Persekutuan Malaysia tetapi ianya dikecualikan ke atas Sabah dan Sarawak, Bahasa Melayu adalah Bahasa rasmi Persekutuan Malaysia, tetapi Bahasa Inggeris akan digunakan sebagai bahasa rasmi di Sabah dan Sarawak, sistem pendidikan dikekalkan di bawah kawalan kerajaan pusat kecuali di Sabah dan Sarawak. Dengan erti kata lain, sistem pendidikan di Sabah dan Sarawak kekal di bawah kawalan kerajaan negeri masing-masing sehingga Majlis Negeri 
membuat pindaan. Di samping itu, di dalam Parlimen Malaysia sebanyak 16 kerusi hendaklah diperuntukkan kepada Sabah, 24 kerusi kepada Sarawak dan 15 kerusi kepada Singapura. Seterusnya bidang kuasa imigresen haruslah kekal terletak di bawah kerajaan pusat tetapi Sabah dan Sarawak diberi kuasa-kuasa tersendiri untuk mengendalikan hal-ehwal imigresen (Jabatan Perdana Menteri Malaysia, 2019).

Dalam konteks hubungan Sabah Sarawak dan Tanah Melayu, Gerakan Sabah Sarawak Keluar Malaysia (SSKM) melihat kerajaan persekutuan yang berpusat di Putrajaya tidak menghormati dan merealisasikan hak-hak yang dimiliki oleh Sabah Sarawak sebagaimana yang termaktub dalam Perjanjian Malaysia 1963 (Yee, 1991; Zainnal, 2015). Kerajaan Persekutuan sebaliknya meneroka hasil bumi dan kekayaan kedua-dua negeri ini melalui konsep federalisme dan mengabaikan agenda pembangunan negeri dengan tidak mengagihkan keuntungan atau pulangan yang setimpal kepada kerajaan negeri dan rakyat negeri Sarawak dan Sabah sebagaimana yang dipersetujui sebelum ini (Mohammad \& Anantha, 2019; Zainnal, 2015). Keuntungan daripada hasil muka bumi Sabah dan Sarawak ini sebaliknya telah digunakan untuk memajukan negeri di Tanah Melayu terutamanya dari segi infrastruktur, teknologi, sistem pengangkutan, pembanguna wilayah, pelaburan, pembangunan fizikal dan kemudahan moden (Zainnal, 2015).

Manakala, Sabah dan Sarawak terus ketinggalan dari segi prasarana dan kemudahan asas hinggakan kedua-dua negeri ini dianggap sebagai negeri yang paling miskin dan mempunyai kadar kemiskinan tegar yang tinggi di Malaysia dengan peratusan yang dicatatkan pada tahun 2016 ialah sebanyak 2.9 \% bagi Sabah dan 0.9 \% bagi Sarawak (Jabatan Perangkaan Malaysia, 2016; Sarawak, 2015). Sehubungan dengan itu, persoalan utama yang timbul dalam kajian ini ialah adakah kewujudan gerakan pemisah SSKM (Sabah Sarawak Keluar Malaysia) ini timbul disebabkan oleh ketidakseimbangan pembangunan ekonomi antara negeri Sabah Sarawak dan Semenanjung Malaysia ataupun disebabkan oleh perbezaan pemahaman tentang konsep federalisme dan agenda Borneo itu sendiri yang anti kepada kolonialisme oleh kerajaan persekutuan. Persoalan-persoalan ini kemudiannya telah menjadi fokus utama dalam kajian ini.

\section{Kaedah dan kawasan kajian}

Bahagian Serian merangkumi Serian, Tebedu dan daerah kecil Siburan. Bahagian Serian telah diisytiharkan sebagai bahagian ke-12 Sarawak oleh Ketua Menteri Sarawak, Tan Sri Datuk Amar Patinggi Hj Adenan bin Hj Satem pada 11 April 2015 (Sarawak, 2015). Bahagian Serian ditadbir oleh seorang Residen (Sarawak Development Corridor, 2008). Setiap daerah ditadbir oleh Pegawai Daerah. Manakala, Daerah Kecil pula ditadbir oleh Pegawai Tadbir (Sarawak, 2015). Bahagian Serian mempunyai seorang Ahli Parlimen dan 3 orang Ahli Dewan Undangan Negeri (Sila lihat Rajah 1). Dari segi pengagihan kursi politik pula Parlimen Serian diwakili oleh Parti SUPP (Sarawak United People Party) dan ketiga-tiga kursi untuk Dewan Undangan Negeri mewakili Parti Pesaka Bumiputera Bersatu (PBB). 


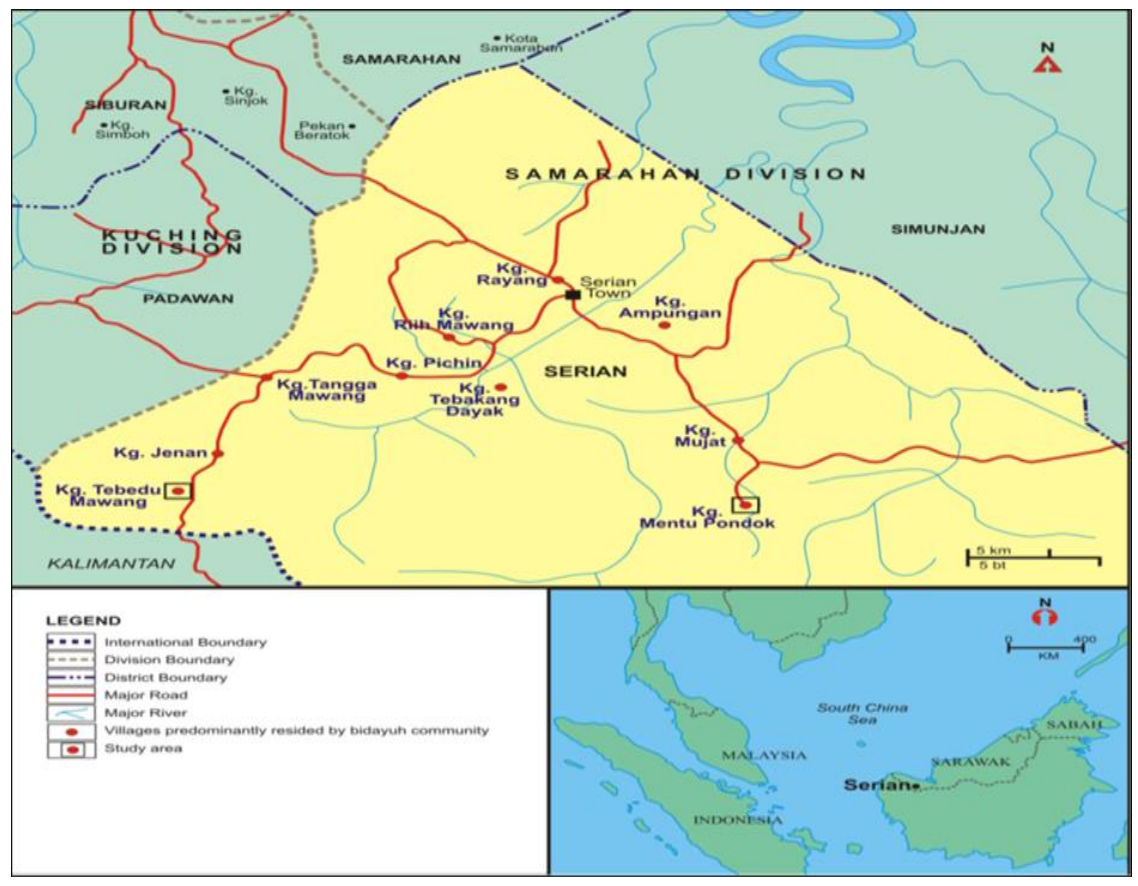

Rajah 1: Lokasi Kajian Bahagian Serian, Sarawak

Dari segi sejarah awal penubuhannya sebelum diisytiharkan sebagai Bahagian, Daerah Serian ditubuhkan pada tahun 1901 dan dikenali sebagai Daerah Sadong disebabkan lokasinya yang berdekatan dengan bukit Sadong dan sungai Kayan (Sarawak, 2004; Sarawak 2007). Daerah Serian telah dipecahkan kepada dua daerah kecil yang dikenali sebagai Serian dan Simunjan (Sarawak Development Corridor, 2008). Keluasan Daerah Serian adalah seluas 2,106 kilometer persegi dan jaraknya dengan Bandaraya Kuching iaitu pusat pentadbiran kerajaan negeri ialah kira-kira 64 kilometer. Daerah Serian sebelum penaiktarafannya kepada Bahagian terkenal dengan aktiviti ekonomi berasaskan pertanian komersial seperti lada hitam, getah dan kelapa sawit (Sarawak 2014; Sarawak 2015). Lokasi Daerah Serian yang berhampiran dengan Sempadan Malaysia-Indonesia dilihat telah menyebabkan daerah ini mempunyai budaya yang pelbagai dan membantu merancakkan pertumbuhan ekonomi di daerah ini berasaskan ekopelancongan, pertanian dan hasil hutan (Sarawak Development Corridor, 2008; Sarawak, 2015).

Manakala, Daerah Kecil Tebedu terletak kira-kira 43 kilometer dari Bandar Serian dan merupakan pintu masuk utama antara Sempadan Malaysia dan Indonesia. Daerah Serian secara amnya bersempadan dengan Bahagian Kuching di kawasan utara, Daerah Simunjan di kawasan timur dan Kalimantan Barat, Indonesia di kawasan selatan (Sarawak Development Corridor, 2008). Daerah Serian mempunyai sebuah bandar utama dan tujuh pekan kecil yang menjadi pusat urusniaga penduduk daerah ini (Sarawak, 2007). Bandar utama tersebut dikenali sebagai Bandar Serian dan merupakan antara salah satu daripada bandar di Sarawak yang dipilih dalam Program Bandar Sejahtera atau Bandar Selamat sejak tahun 2001. Populasi penduduk di Bahagian Serian berdasarkan statistik bagi tahun 2016 adalah sebanyak 150,305. Daripada jumlah tersebut $70 \%$ adalah daripada etnik Bumiputera yang terdiri daripada Bidayuh, Iban dan Orang Ulu, etnik Melayu sebanyak 17\% dan etnik Cina sebanyak 12\% (Jabatan Perangkaan Malaysia, 2016). 
Strategi penyelidikan abduktif berdasarkan ontologi idealis dan epistemologi konstruksionis telah dipilih untuk digunakan dalam kajian ini bagi merungkaikan realiti sosial yang perlu dilihat melalui pandangan dunia informan yang dijelmakan oleh pengalaman hidup, interaksi sosial, pengaruh agen sosialisasi dan persekitaran sosial mereka sendiri (Blaikie, 2010). Data telah dikumpul menggunakan kaedah temu bual mendalam dan perbincangan kumpulan terfokus berdasarkan panduan soalan yang telah dibina. Data yang diperolehi dalam kajian ini adalah berbentuk kualitatif di mana setiap perbualan yang dirakam melalui teknik pengumpulan data temubual mendalam akan diterjemahkan ke dalam bentuk teks. Populasi kajian ini terdiri adalah daripada etnik Bidayuh dialek Bukar Sadong yang tinggal di dua kawasan penempatan utama di Bahagian Serian iaitu di kawasan bandar dan luar bandar. Penentuan tentang kawasan mana yang bandar dan luar bandar ini diperolehi daripada Pejabat Residen, Bahagian Serian, Sarawak. Sejumlah 50 orang etnik Bidayuh dialek Bukar Sadong telah terlibat dan dipilih dalam kajian ini menggunakan persampelan berstrata, bertujuan dan bola salji. Jumlah informan ini terhasil berlandaskan konsep ketepuan data yang mana jawapan yang diberikan adalah sama dan berulang-ulang. Sejumlah 25 orang etnik Bidayuh tinggal di kawasan bandar dan 25 orang lagi tinggal di kawasan pedalaman. Kesemuanya berumur dalam lingkungan 20 tahun ke atas dan mereka terdiri daripada pelbagai latar belakang yang berbeza bukan sahaja dari segi pekerjaan malah turut melibatkan jantina dan taraf pendidikan. Perbezaan latar belakang ini penting bagi memastikan konsep atau fahaman mereka tentang sesuatu realiti sosial itu daripada sudut pandang yang berbeza. Kesemua transkrip yang ditulis dalam Bahasa Bidayuh dialek Bukar Sadong seterusnya diterjemahkan ke dalam Bahasa Melayu oleh penterjemah profesional yang terdiri daripada komuniti Bidayuh itu sendiri. Terjemahan ini kemudiannya akan dihantar kepada pakar Bahasa Melayu untuk tujuan kejelasan dan bagi memastikan terjemahan tersebut sahih dan boleh dipercayai sepenuhnya. Kesemua data yang telah ditranskripsikan akan dianalisa menggunakan perisian Nvivo secara analitikal dan komprehensif berdasarkan analisis tematik dan verbatim.

\section{Hasil kajian dan perbincangan}

Hasil kajian mendapati, terdapat tiga pandangan utama yang dilontarkan oleh etnik Bidayuh di Bahagian Serian tentang Gerakan Sabah Sarawak Keluar Malaysia (SSKM). Kesemua pandangan ini diasaskan oleh empat faktor utama iaitu marginalisasi, diskriminasi, pengasingan dan peminggiran dalam bentuk politik, ekonomi dan sosial oleh kerajaan persekutuan yang kemudiannya diterjemahkan sebagai kolonial Malaya. Ketiga-tiga pandangan tersebut ialah untuk menuntut hak Sarawak sebagai rakan sekutu dalam Pembentukan Negara Malaysia yang telah termaktub dalam Perjanjian Malaysia 1963, desakan terhadap kerajaan persekutuan supaya menghormati 18 perkara untuk Sarawak melalui saluran undang-undang sebagaimana yang terkandung dalam Perjanjian Malaysia 1963 dan sebagai alat untuk menyampaikan perasaan tidak puas hati terhadap dasar dan polisi pentadbiran kerajaan pusat yang menganaktirikan pembangunan rakyat di kedua-dua buah negeri ini. Pandangan ini timbul disebabkan oleh sikap kerajaan persekutuan itu sendiri yang masih lagi berdolak dalih dan meletak taraf negeri Sarawak sebagai bukan rakan sekutu dalam pembentukan negara Malaysia. Dalam masa yang sama, tidak memberi pengiktirafan kedudukan negeri Sarawak melalui saluran undang-undang terhadap Perkara 18 yang terkandung dalam Perjanjian Malaysia 1963. Pembentukan Gerakan Sabah Sarawak Keluar Malaysia ini bukanlah medium untuk orang Sabah dan Sarawak menuntut untuk 
leluar dari Malaysia ataupun memohon autonomi sepenuhnya namun sebagai landasan agar suara-suara rakyat Sabah dan Sarawak didengari dan dihormati terutamanya dari segi kebajikan, kebolehsampaian terhadap infrastruktur dan hak terhadap hasil bumi di kedua-dua negeri ini.

Menuntut hak sebagai rakan sekutu dalam Pembentukan Negara Malaysia yang telah termaktub dalam Perjanjian Malaysia 1963

Majoriti informan dalam kajian ini menyatakan kelahiran Gerakan Sabah Sarawak Keluar Malaysia (SSKM) adalah susulan daripada sikap dan tindakan kerajaan persekutuan itu sendiri yang tidak menghormati negeri Sarawak sebagai rakan sekutu dalam tempoh yang agak lama sebagaimana yang terkandung dalam Perjanjian Malaysia 1963. Dalam masa yang sama, pemahaman rakyat di kedua-dua buah negeri iaitu di Sabah dan Sarawak tentang Perjanjian Malaysia 1963 adalah sangat lemah. Keadaan ini menyebabkan maklumat dan pengetahuan mereka banyak bergantung kepada media baru dan realiti sosial yang berlaku dalam kehidupan mereka. Kemunculan media baru melalui saluran internet telah merancakkan lagi perbincangan oleh rakyat di negeri Sarawak tentang hak dan kuasa sebagai rakan sekutu dalam pembentukan negara Malaysia. Keadaan ini telah menyebabkan mereka perlu berfikir untuk melahirkan sebuah NGO yang tidak memihak mana-mana parti-parti politik tetapi meletakkan agenda Borneo atau agenda Sarawak sebagai asas kepada perjuangan mereka. Dalam masa yang sama, tuntutan rakyat Sarawak dalam Perkara 18 tentang hak-hak dan kuasa negeri Sarawak dalam Persekutuan Malaysia telah diabaikan oleh kerajaan persekutuan.

Alasan-alasan ini telah dijadikan modal oleh kumpulan gerakan pemisah SSKM untuk mendapatkan perhatian rakyat negeri Sarawak melalui Agenda Borneo atau Agenda Sarawak yang bertentangan dengan semangat federalisme. Tambahan pula budaya politik berasaskan patrion-klien melalui konsep kebergantungan telah menyebabkan gerakan pemisah SSKM menjadi terkenal dan mendapat sambutan yang sangat baik daripada rakyat negeri Sarawak yang pelbagai etnik. Misalnya, Informan R7 dan R8 berpendapat bahawa kemunculan Gerakan Sabah Sarawak Keluar Malaysia (SSKM) ini disebabkan oleh sikap kerajaan persekutuan yang tidak menghormati negeri Sarawak sebagai rakan sekutu pembentukan negara Malaysia. Hal ini menyebabkan Gerakan SSKM ini adalah landasan terbaik untuk menyuarakan perasaan tidak puas hati dan menuntuk semula janji-janji yang telah dinyatakan oleh kerajaan persekutuan melalui manifesto pilihanraya sejak Sarawak berada dalam sistem federalism berasaskan sistem politik demokratik. Dalam masa yang sama, suara ini akan dapat didengar dengan jelas oleh kerajaan pusat di Putrajaya.

Dalam nada yang sama, R2 pula menyuarakan sokongan tidak berbelah bagi beliau terhadap gerakan membawa Sarawak keluar dari Malaysia. Hal ini kerana kewujudan Gerakan SSKM telah menyatukan orang Sarawak tanpa mengira etnik dan taraf sosio-ekonomi untuk membuat tuntutan terhadap kerajaan pusat dan ini adalah merupakan langkah yang terbaik untuk memberi kesedaran kepada rakat di Sarawak. Di samping itu ia memberi ruang kepada rakyat Sarawak untuk menyuarakan pandangan dan pemikiran mereka dalam memperjuangkan semula hak mereka yang terabai sejak sekian lama sama ada melalui parti politik mahupun melalui media massa. Seterusnya R4 juga berpendapat bahawa gerakan ini adalah tuntutan atau hasrat daripada rakyat Sarawak yang ingin hak dan kuasa-kuasa yang terkandung dalam Perlembagaan Malaysia dikembalikan. Mereka mahu Perkara 18 yang terkandung dalam Perjanjian Malaysia 1963 dihormati dan direalisasikan dengan jujur oleh kerajaan persekutuan. R4 kemudiannya menyatakan bahawa sebagai rakan sekutu dalam pembentukan Malaysia, rakyat Sarawak 
haruslah dibawa berbincang bagi menentukan perkara yang mereka inginkan dan bukannya hanya sebagai penerima rancangan pembangunan. Dalam masa yang sama, pembangunan luar bandar dan kemudahan infrastruktur di negeri Sarawak masih lagi dalam keadaan daif walaupun sudah 56 tahun pembentukan Negara Malaysia.

Keadaan ini telah menjadi asas kepada lahirnya Gerakan SSKM. Ketidakpuashatian mereka terhadap layanan kerajaan persekutuan terhadap Sarawak dan Sabah telah diterjemahkan dalam Gerakan SSKM. Penubuhan Gerakan SSKM ini bukan untuk membawa Sabah dan Sarawak keluar daripada Malaysia, tetapi sebagai alat untuk menyedarkan kerajaan persekutuan supaya tidak mengabaikan kebajikan dan pembangunan ekonomi negeri Sarawak. Nada yang sama turut dilontarkan oleh R9 dan R11 yang menyatakan bahawa bahawa kewujudan isu Sarawak keluar dari Malaysia ini adalah disebabkan oleh wujudnya rasa ketidakpuasan hati masyarakat Sarawak terhadap pentadbiran kerajaan persekutuan. Ketidakpuashatian ini telah diterjemahkan dalam Gerakan SSKM dengan harapan supaya kerajaan persekutuan mendengar masalah dan isu yang dihadapi oleh rakyat negeri Sarawak terutamanya dari segi isu-isu yang berkaitan dengan tanah, peruntukan, pengagihan ekonomi, kebajikan, kebolehsampaian terhadap infrastruktur dan peluang pekerjaan yang saksama dalam sektor perkhidmatan awam. Dalam masa yang sama juga, maklumat-maklumat yang dimuatkan oleh Gerakan SSKM tentang diskriminasi dan peminggiran terhadap hak Sarawak dan keuntungan yang dikutip oleh kerajaan persekutuan terhadap hasil minyak negeri Sarawak telah menyebabkan ramai anak-anak muda sudah mula ambil tahu terhadap halatuju negeri Sarawak dalam negara Malaysia. Rata-rata informan menyokong tuntutan yang dikemukakan oleh Gerakan SSKM dan mula sedar tentang pentingnya NGO yang berani membangkitkan isu-isu yang sensitif yang boleh menjejaskan hubungan antara kerajaan persekutuan dan negeri Sarawak. Perkara inilah yang menyebabkan Gerakan SSKM mendapat sambutan yang cukup baik dalam kalangan rakyat Sarawak.

Desakan terhadap kerajaan persekutuan supaya menghormati 18 perkara untuk Sarawak yang terkandung dalam Perjanjian Malaysia 1963

Rata-rata informan dalam kajian ini berpandangan bahawa isu Sarawak keluar dari Malaysia ini perlu diwujudkan secara agresif dan disensasikan terutamanya melalui media baru untuk mendesak kerajaan persekutuan supaya meratifikasikan 18 perkara yang terkandung dalam Perjanjian Malaysia 1963 melalui saluran perlembagaan. Desakan yang dilakukan melalui Gerakan SSKM ini walaupun nampak terlalu keras namun asas kepada perjuangannya ialah untuk memastikan rakyat negeri Sarawak menikmati kemakmuran dan kualiti hidup yang sama sebagaimana yang dirasai oleh rakyat di Semenanjung Malaysia. Perkara ini telah dilontarkan oleh R7 yang menyatakan bahawa gerakan Sarawak keluar dari Malaysia perlu dijelmakan sebagai satu isyarat untuk menekan kerajaan persekutuan supaya mengotakan janji-janji mereka bagi memastikan rakyat Sarawak tidak ketinggalan dalam arus pembangunan terutamanya melibatkan 18 Perkara yang terkandung dalam Perjanjian Malaysia 1963.

Hal ini adalah merupakan perkara pokok atau asas kepada federalisme di mana Sarawak secara rasminya bersetuju untuk diturun taraf menjadi negeri dalam Persekutuan Malaysia. Persetujuan inilah yang menyebabkan negeri Sarawak sepatutnya tidak boleh dilihat mempunyai taraf yang sama dengan negeri-negeri lain dalam Malaysia. Negeri Sarawak adalah merupakan rakan sekutu yang membentuk Malaysia bersama-sama dengan Semenanjung Tanah Melayu, Singapura dan Sabah. Syarat-syarat yang dikenakan oleh negeri Sarawak untuk bergabung dengan Semenanjung Tanah Melayu, Sabah dan Singapura adalah perkara asas kepada lahirnya 
negara Malaysia yang berdaulat. Oleh itu, amat wajar kerajaan persekutuan menghormati 18 Perkara tersebut dan merealisasikannya dalam semangat rakan sekutu. Dalam nada yang sama, R10 turut membangkitkan sentimen yang menyatakan bahawa negeri Sarawak ini telah dijajah oleh orang dari Semenanjung Malaysia melalui proses kolonialisasi yang menidakkan penyertaan etnik Bumiputera dalam pembangunan ekonomi terutamanya dalam industri berat dan sederhana.

Pembangunan pesat yang berlaku di Semenanjung Malaysia telah dijadikan modal perbandingan dalam mengukur pembangunan dan modenisasi yang berlaku di Sarawak. Negeri Sarawak masih lagi dilihat ketinggalan dalam pembangunan ekonomi, kebolehsampaian terhadap infrastruktur dan pendidikan. Hampir 80 peratus sekolah-sekolah di Sarawak masih lagi dalam keadaan daif dan perlu dinaiktarafkan agar selari dengan hasrat kerajaan melahirkan modal insan yang berkebolehan dan memenuhi pasaran revolusi industry 4.0. Perkara ini telah dinyatakan oleh R11 dan R6 yang menyatakan bahawa minat mereka terhadap Gerakan SSKM ini bukanlah untuk membawa Sarawak keluar daripada Malaysia, tetapi untuk mendesak kerajaan persekutuan supaya tidak berdegil dalam merealisasikan tanggungjawab untuk membangunkan ekonomi Sarawak dan mensejahterakan rakyat Sarawak melalui pembangunan modal insan dan penyediaan peluang pekerjaan. Desakan melalui Gerakan SSKM ini perlu diteruskan dan dipergiatkan agar suara mereka terus didengar sama ada oleh kerajaan persekutuan mahupun oleh pihak antarabangsa.

Medium luahan rasa tidak puas hati terhadap pentadbiran kerajaan pusat yang menganaktirikan pembangunan rakyat Sarawak

Isu Sarawak keluar dari Malaysia ini juga dijadikan sebagai medium untuk Orang Sarawak meluahkan rasa tidak puas hati mereka kepada pentadbiran kerajaan pusat. Hal ini kerana isu ini sudah banyak kali dibangkitkan oleh para pemimpin daripada parti politik di Sarawak sama ada daripada parti kerajaan mahupun pembangkang di Parlimen dan di Dewan Undangan Negeri namun isu ini tidak diberi perhatian utama oleh kerajaan persekutuan. Negeri Sarawak masih lagi dikategorikan sebagai negeri termiskin di Malaysia walaupun mempunyai hasil bumi yang banyak. Ramai anak-anak muda terpaksa berhijrah ke Semenanjung Malaysia untuk mencari pekerjaan disebabkan peluang pekerjaan di negeri Sarawak adalah terhad dan terbatas kepada belia yang mempunyai pendidikan yang tinggi. Dalam masa yang sama, peluang pekerjaan dalam agensi kerajaan persekutuan juga banyak dimonopoli oleh orang-orang dari Semenanjung Malaysia terutamanya daripada etnik Melayu.

Keadaan ini menyebabkan mereka melihat perkembangan ini sebagai agenda Malaya atau campurtangan Semenanjung Malaysia secara senyap terhadap pentadbiran dan urus tadbir negeri Sarawak. Pentadbiran kerajaan persekutuan dilihat lebih banyak melabur dan membangunkan negeri-negeri di pantai barat Semenanjung Malaysia dan mengabaikan pembangunan wilayah di Negeri Sarawak, Sabah dan negeri di pantai timur Semenanjung Malaysia. Di samping itu, penyediaan kemudahan asas dan penaiktarafan infrastruktur yang merupakan bidang kuasa kerajaan persekutuan telah digerakkan secara perlahan dan tidak konsisten dengan ekosistem negeri Sarawak itu sendiri. Keadaan ini secara berterusan telah menyemarakkan perasaan tidak puas hati terhadap kerajaan persekutuan dalam kalangan rakyat Sarawak. Justeru itu jalan terbaik bagi menyatakan kemarahan dan ketidakpuashatian mereka adalah melalui Gerakan SSKM.

Walaupun begitu, terdapat juga segelintir informan yang tidak menyokong Gerakan SSKM ini sepenuhnya. Misalannya, R1, R2, R22 dan R23, menyatakan yang mereka tidak menyokong sepenuhnya Gerakan SSKM ini. Hal ini kerana gerakan ini menyebabkan wujudnya konflik 
dalaman antara kerajaan negeri dan kerajaan persekutuan. Tambahan pula, kerajaan negeri dan kerajaan persekutuan ditadbir oleh parti politik yang sama sebelum wujudnya peralihan kuasa di kerajaan persekutuan pada tahun 2018 daripada Barisan Nasional kepada Pakatan Harapan. Oleh itu, mereka berpandangan bahawa isu-isu Sarawak ketinggalan dalam pembangunan, hak-hak negeri Sarawak telah dicabul dan kebajikan orang Sarawak tidak dijaga sepenuhnya patut diletak di bawah bahu kerajaan negeri. Parti yang memerintah kerajaan negeri adalah parti yang sama memerintah kerajaan persekutuan sebelum Pilihanraya Umum (PRU) 14. Kerajaan negeri sepatutnya menggunakan cara diplomasi dan berunding sebagai seorang sahabat atau rakan sekutu dalam membincangkan tentang hak-hak negeri Sarawak sebagaimana yang terkandung dalam Perkara 18 Perjanjian Malaysia 1963.

\section{Kesimpulan}

Terdapat tiga kesimpulan utama yang boleh diperolehi dalam kajian ini. Kesimpulan yang pertama ialah pandangan yang diutarakan oleh etnik Bidayuh tentang Gerakan SSKM ini bukanlah merupakan perkara baru. Gerakan SSKM hanyalah sebagai alat atau referendum untuk menyuarakan perasaan tidak puas hati rakyat Sarawak disebabkan hilang keyakinan terhadap komitmen parti-parti politik berasaskan etnik dan kenegerian di Sarawak dalam mendesak kerajaan persekutuan untuk menghormati dan melaksanakan hak-hak Sarawak sebagaimana yang terkandung dalam Perjanjian Malaysia 1963. Namun pada ketika itu, ketidakpuashatian mereka terhadap sikap kerajaan persekutuan dibangkitkan secara senyap-senyap dan tidak tersusun melalui parti politik masing-masing yang bersifat kenegerian tanpa melalui saluran media, gerakan berasaskan media sosial dan persatuan berdaftar. Dalam masa yang sama, kebanyakkan isu-isu yang disentuh agah umum iaitu terhad kepada agenda Sarawak atau agenda Borneo.

Kekalahan parti Barisan Nasional pada PRU14 baru-baru ini kemudiannya telah merancakkan lagi tuntutan rakyat Sarawak secara terbuka melalui perhimpunan di jalanan terhadap 18 perkara dalam Perjanjian Malaysia 1963 sama ada melalui saluran parti pemerintah di peringkat negeri dan parti pembangkang yang menjadi kerajaan di peringkat persekutuan. Kesimpulan yang kedua ialah pengetahuan dan maklum balas komuniti Bidayuh terhadap Gerakan SSKM adalah lahir implikasi daripada penggunaan media sosial yang kini mendapat sambutan yang sangat menggalakkan daripada golongan muda dan remaja. Golongan inilah yang menjadi saluran dan tunjang maklumat kepada para ibu bapa dan masyarakat di kawasan luar bandar dan bandar tentang Perjanjian Malaysia 1963 dan isu-isu yang menyentuh tentang hakhak Sarawak dalam Perlembagaan Malaysia dan kedudukan Bumiputera Sarawak berdasarkan peruntukan perundangan dari segi sosio-ekonomi.

Akhir sekali, kesimpulan yang ketiga ialah pandangan etnik Bidayuh terhadap Gerakan SSKM banyak didorong oleh dua faktor yang utama iaitu agenda kenegerian dan agenda federalisme yang kadangkala tidak sampai dan tidak difahami sepenuhnya oleh rakyat Sarawak. Agenda kenegerian menyentuh tentang hak-hak dan kuasa kerajaan negeri sebagaimana yang dinyatakan dengan jelas dalam Perjanjian Malaysia 1963. Manakala agenda federalisme menyentuk tentang peranan dan tanggungjawab kerajaan persekutuan sebagaimana yang terkandung dalam Perlembagaan Malaysia terhadap pembangunan ekonomi dan penyediaan modal insan untuk rakyat negeri Sarawak dan bukannya berpaksikan kepada agenda etnik majoriti semata-mata. 


\section{Penghargaan}

Kajian ini telah disokong sepenuhnya oleh Universiti Kebangsaan Malaysia melalui peruntukan Kursi Endowmen MPOB-UKM, Kod Projek: EP-2017-034.

\section{Rujukan}

Azizah K. (2009). Filipino refugees in Sabah: State responses, public stereotypes and the dilemma over their Future. Southeast Asian Studies, 47, 58.

Bilson, K. (1998). Migrant labor: The Sabah experience. Asian and Pacific Migration Journal, 7 , 281-295.

Blaikie, N. (2010). Designing Social Research. Edisi-2. United Kingdom: Polity Press.

Catherine, A. (2014). Statelessness and the lives of the children of migrants in Sabah, East Malaysia. Tilburg Law Review: Journal of International and European Law, 19(1-2), 2634.

Ismail, Y. (1997). Politik dan Agama di Sabah. Bangi: Penerbit Universiti Kebangsaan Malaysia.

Jabatan Perangkaan Malaysia. (2016). Statistik Kemiskinan dan Populasi Penduduk Mengikut Negeri. http://www.data.gov.my/data.

Jabatan Perdana Menteri Malaysia. (2019). Perjanjian Malaysia 1963. https://www.pmo.gov.my/dokumenattached/Artikel/MA63.pdf

Jacqueline Ann Surin. (2014). Uncommon Sense with Wong Chin Huat: Can Sabah and Sarawak secedes? March 3, 2014. Atas talian: http://www.thenutgraph.com/uncommon-sense-withwong-chin-huat-can-sabah-and-sarawak-secede/.

Ong, P.L., \& Badariah, S. (2016). Saexit - Sabah dan Sarawak Keluar Malaysia: Tinjauan Atas

Talian Pandangan Orang Sabah dan Sarawak. Kertas kerja dibentangkan di Perbincangan Meja Bulat Federalisme dan Isu Hak Negeri. Anjuran Institut Kajian Etnik pada 14 April 2016 di Hotel Bangi Putrajaya - Bangi.

Kasmila, A. (1980). Politik Sabah Tahun 80an (Sabah tanpa Syed Kechik). Kuala Lumpur. Dewan Bahasa dan Pustaka: Kuala Lumpur.

Lee, E. (1976). The Towkays of Sabah: Chinese leadership and indigenous challenge in the last phase of British Rule. Singapore: Singapore University Press Ptd Ltd,.

Leong, C. (1982). SABAH, The first 100 years. Kuala Lumpur: Percetakan Nan Yang Muda Sdn. Bhd.

Lim R. (2008). Federal-State relations in Sabah, Malaysia: The Berjaya Administration, 197685. Singapore: ISEAS Publishing.

Matthew, G. (2009). Statelessness and the right to citizenship. Migration Review, 50, 50.

Mohammad, S., \& Anantha, R.G. (2019). Sabah Sarawak Keluar Malaysia (SSKM): Hala Tuju Selepas Pru14. Jurnal Kinabalu, 24, 1-16.

Rahman, A.T.A., \& Pandikar A.M. (2019). Isu Perjanjian Malaysia 1963 (MA63) dan Hak Autonomi Sabah dan Sarawak dalam Konteks Sejarah dan Pru-14, Jurnal Kinabalu, 24, 121.

Ramli, D. (2003). Isu Keselamatan persempadan Negeri Sabah dan tuntutan terhadap kepulauan Spartly. Kota Kinabalu: Penerbit Universiti Malaysia Sabah. 
Ramzah, D. (2010). Sabah Priority Issues: Setting the course for change. Kota Kinabalu: CCS Printing Sdn. Bhd.

Rosaini, M. (2009). Pola perniagaan pendatang asing di Sabah. Kota Kinabalu: Penerbit Universiti Malaysia Sabah.

Sarawak Development Corridor. (2008). Koridor Pembangunan Sarawak: Rangka Tindakan Sosioekonomi 2008-2025. Institut Pembangunan Sarawak (SDI). 5 Februari. 1-8.

Sarawak. (2004). Department of Statistics. Population and housing census of Malaysia, 2004, Kuala Lumpur: Gov't Printing Office.

Sarawak. (2007). Department of Statistics. Population and housing census of Malaysia, 2007, Kuala Lumpur: Gov't Printing Office.

Sarawak. (2014) Department of Statistics. Population and housing census of Malaysia, 2014, Kuala Lumpur: Gov't Printing Office.

Sarawak. (2015). Department of Statistics. Population and housing census of Malaysia, 2015, Kuala Lumpur: Gov't Printing Office.

Yee, S. (1991). Joseph Pairin Kitingan, The making of a Malaysian. Perpustakaan Negara Malaysia. Foto Technik Sdn Bhd.

Zainnal, A. (2015). The Queen's Obligation and the Inter-Governmental Committee Report. Kota Kinabalu, Sabah: BruConn Sdn Bhd

Zaini, O. (2010). Nasionalisme, Etnisiti dan Komuniti Sempadan Negeri Sabah. Kota Kinabalu: Universiti Malaysia Sabah 